\title{
Cobalt-based ZIF-68 and ZIF-69 as the precursors of non-platinum electrocatalysts for oxygen reduction
}

\author{
Yulia A. Pimonova, ${ }^{* a, b}$ Tatiana A. Lastovina, ${ }^{* a, c}$ Andriy P. Budnyk, ${ }^{c}$ \\ Egor A. Kudryavtsev ${ }^{d}$ and Maxim N. Yapryntsev ${ }^{d}$ \\ ${ }^{a}$ International Research Center 'Smart Materials', Southern Federal University, 344090 Rostov-on-Don, \\ Russian Federation. E-mail: lastovina@sfedu.ru \\ ${ }^{b}$ Department of Chemistry, Southern Federal University, 344090 Rostov-on-Don, Russian Federation \\ ${ }^{c}$ Southern Scientific Center, Russian Academy of Sciences, 344006 Rostov-on-Don, Russian Federation \\ ${ }^{d}$ Belgorod National Research University, 308015 Belgorod, Russian Federation
}

\begin{abstract}
We report the microwave-assisted synthesis of Co-based ZIF-68 and ZIF-69 zeolitic imidazolate frameworks, which were enriched with iron(II) acetate and 1,10-phenanthroline and then pyrolyzed to form heterogeneous catalysts. The materials demonstrated high activity in oxygen reduction and suitability as Pt-free catalysts for low-temperature fuel cells.
\end{abstract}

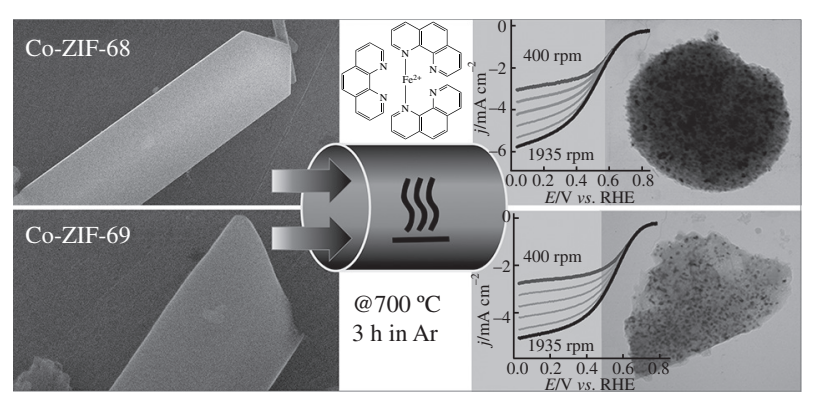

The morphology of products was observed by electron microscopy (Figure 1). The SEM image of CoZ-68 [Figure 1(a)] demonstrates rod-shaped crystallites with an average length of $9-11 \mu \mathrm{m}$ and a width of $2-4 \mu \mathrm{m}$. Note that a number of crystallites seems broken, while some large hexagonal rods propagate up to $21 \mu \mathrm{m}$. In addition to the rods, there are small round-like particles (Figure S1, see Online Supplementary Materials). The STEMEDX mapping (Figure S2) demonstrated a homogeneous distribution of $\mathrm{Co}, \mathrm{Fe}, \mathrm{C}$, and $\mathrm{N}$ across the material. As for CoZ69 [Figure 1(b)], smaller elongated crystallites with rounded ends and average dimensions of $4 \times 1 \mu \mathrm{m}$ were observed.

\footnotetext{
Commercial reagents were used as received. (i) Synthesis of CoZ-68. $\mathrm{Co}\left(\mathrm{NO}_{3}\right)_{2} \cdot 6 \mathrm{H}_{2} \mathrm{O}(0.2 \mathrm{mmol})$ was dissolved in DMF $(1 \mathrm{ml})$ and a composition of 2-nitroimidazole $(0.3 \mathrm{mmol})$ and benzimidazole $(0.2 \mathrm{mmol})$ was dissolved in DMF $(2.5 \mathrm{ml})$. Afterward, the former was added to the latter dropwise. The mixture was loaded in a Discover SP microwave reactor (CEM) and left to react at $135^{\circ} \mathrm{C}$ for $3 \mathrm{~h}$ with stirring. The red-purple precipitate obtained was washed once with DMF and thrice with methanol and dried overnight at $50{ }^{\circ} \mathrm{C}$. (ii) Synthesis of CoZ-69. 2-Nitroimidazole (1.2 mmol), 5-chlorobenzimidazole (1.2 mmol) and $\mathrm{Co}\left(\mathrm{NO}_{3}\right)_{2} \cdot 6 \mathrm{H}_{2} \mathrm{O}(0.6 \mathrm{mmol})$ were dissolved in DMF $(12 \mathrm{ml})$. The mixture was placed in a Discover SP and left to react at $120^{\circ} \mathrm{C}$ for $2 \mathrm{~h}$ with stirring. The resulting dark purple precipitate was triply washed with methanol and dried overnight at $60{ }^{\circ} \mathrm{C}$. (iii) Impregnation with $\mathrm{Fe}^{\mathrm{II}}-$ phenanthroline. $\mathrm{Fe}(\mathrm{OAc})_{2}(0.005 \mathrm{~g})$ and 1,10 -phenanthroline $(0.0315 \mathrm{~g})$ were dissolved in ethanol $(5 \mathrm{ml})$ to form a red solution, and the ZIF powder $(0.125 \mathrm{~g})$ was added. The mixture was sonicated for $30 \mathrm{~min}$, stirred for $1 \mathrm{~h}$, and dried at $60^{\circ} \mathrm{C}$. (iv) Pyrolysis. ZIFs were heated in a tube furnace (Nabertherm) to $700{ }^{\circ} \mathrm{C}$ with a rate of $10{ }^{\circ} \mathrm{C} \mathrm{min}^{-1}$ and kept for $3 \mathrm{~h}$ in an Ar flow.

* X-ray diffraction (XRD) analysis was performed on a SmartLab (Rigaku) diffractometer. Scanning electron microscopy (SEM) was carried out on a Supra 25 (Zeiss) microscope. Transmission electron microscopy (TEM) was performed on a JEM-2100 (JEOL) microscope operated at an accelerating voltage of $200 \mathrm{kV}$.
} 

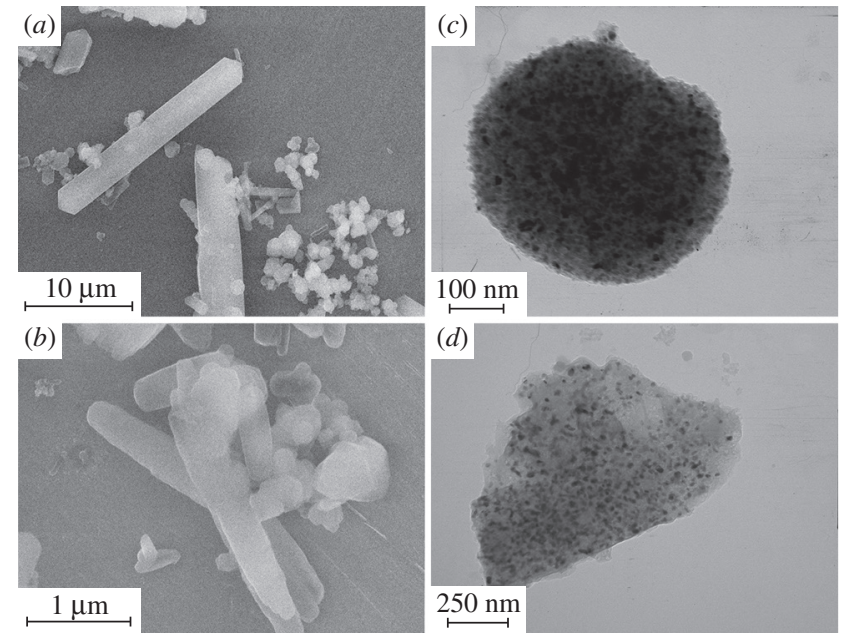

Figure 1 SEM images of $(a)$ CoZ-68 and $(b)$ CoZ-69. TEM images of (c) CoZ-68-C and (d) CoZ-69-C pyrolyzed powders.

Carbonaceous materials were studied by TEM. Both CoZ-68-C and CoZ-69-C consist of carbonaceous globules containing metal NPs (see Figure 1). The particle size distribution (Figure S3) covers a range of 4-22 nm. For CoZ-68-C, it peaks around $8 \mathrm{~nm}$ with a substantial contribution from 6-16 nm particles (Figure S1). There is a well-defined maximum at $16-18 \mathrm{~nm}$ in particle size distribution histogram for CoZ-69-C [Figure S1 $(b)$ ]. The occurrence of relatively large metal NPs can be due to the absence of a separating agent. Zinc is known to play this role in bimetallic ZIFs. ${ }^{3}$

The structure of the samples was assessed with powder XRD (Figure 2). The synthesized MOFs are highly crystalline
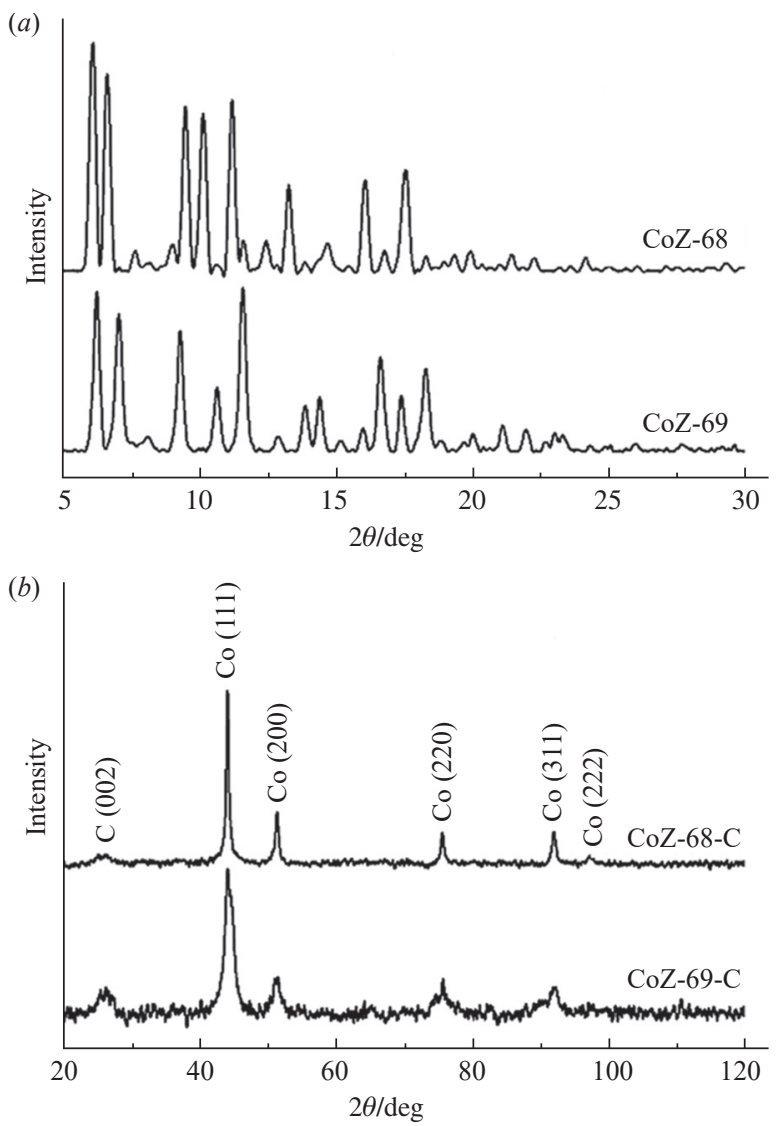

Figure 2 XRD patterns of $(a)$ as-synthesized MOFs and $(b)$ pyrolyzed carbons.
[Figure 2(a)], and their diffraction patterns are consistent with published data for ZIF-68 and ZIF-69. ${ }^{7}$ The diffraction picture of carbonized materials [Figure $2(b)$ ] contains contributions from graphitized carbon and metal NPs formed during the hightemperature treatment. A broad peak at $26.1^{\circ}$ evidences the graphite structure in the spatial symmetry group Fmmm (69) (database card no. PDF-2-9000046). At lager $2 \theta$ angles, there are reflections from a crystalline structure of cobalt in the spatial symmetry group Fm-3m (225) (database card no. PDF-29008466), considering its relatively high loading in respect to iron. The lattice parameters for metal NPs in CoZ-68-C and CoZ-69-C were evaluated as 3.5459 and $3.5485 \AA$, respectively. The values are close to that of pure cobalt, $3.548 \AA$. Although, we cannot exclude the doping of cobalt NPs with iron. No diffraction peaks remained from the original ZIFs, confirming the complete destruction of the ZIF structure. The average sizes of metal NPs were 9.2 and 18.2 nm for CoZ-68-C and CoZ-69-C, respectively.

The Raman spectra of pyrolyzed samples (Figure S3) exhibit characteristic bands at 1349 and $1591 \mathrm{~cm}^{-1}$, which are the disorder-induced D-band and the symmetry-allowed G-band of carbon, respectively. Their intensities are almost equal due to a high level of structure imperfection. Carbon is $\mathrm{sp}^{3}$-hybridized, and it does not form graphite/graphene structures in appreciable quantities.

The electrochemical tests included cyclic voltammetry (CV) and linear sweep voltammetry (LSV) in a potential range of 1.2-0.03 $\mathrm{V}$ vs. RHE with scan rates of 20 and $5 \mathrm{~V} \mathrm{~s}^{-1}$, respectively. ${ }^{\S}$ Prior to the $\mathrm{CV}$ measurements in an $\mathrm{O}_{2}$ atmosphere at a rotation rate of $1600 \mathrm{rpm}$, the pre-cycling was performed
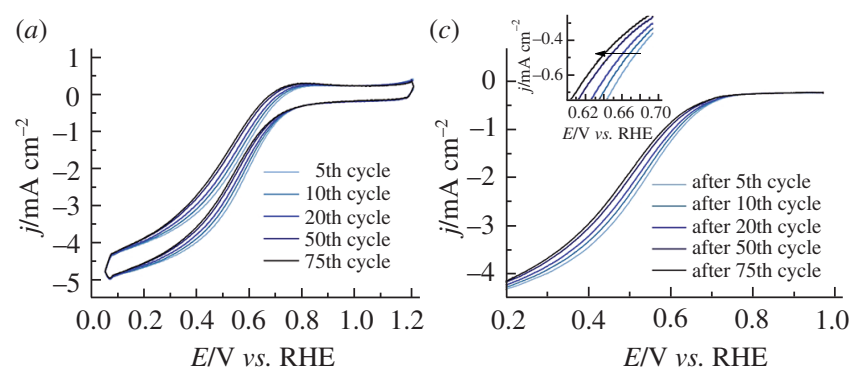

(b)
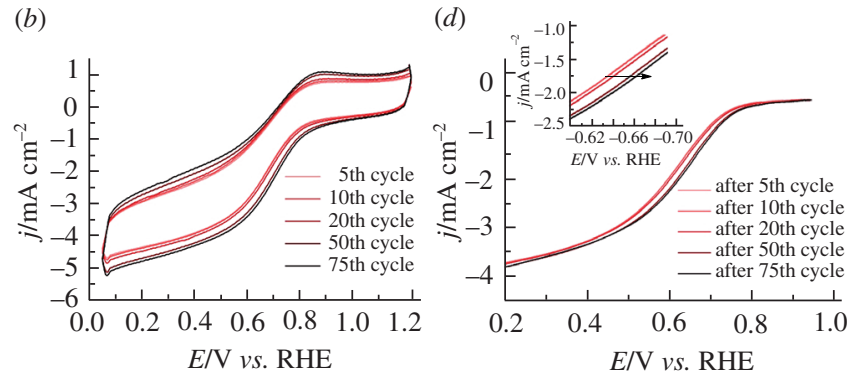

Figure $3 \mathrm{CV}$ curves for (a) CoZ-68-C and (b) CoZ-69-C collected in $0.1 \mathrm{M} \mathrm{HClO}_{4}$ at a scan rate of $20 \mathrm{mV} \mathrm{s}^{-1}, 25{ }^{\circ} \mathrm{C}$ in an $\mathrm{O}_{2}$ atmosphere at a rotation rate of $1600 \mathrm{rpm}$ and the LSV curves for $(c) \mathrm{CoZ}-68-\mathrm{C}$ and (d) CoZ-69-C.

\footnotetext{
$\S$ The electrochemical tests were performed at room temperature using a PARSTAT 4000 potentiostat/galvanostat with a standard three-electrode cell with a rotating disk electrode (RDE) using a $0.1 \mathrm{M} \mathrm{HClO}_{4}$ electrolyte solution. The reference and counter electrodes were $\mathrm{Ag} / \mathrm{AgCl}_{2}$ and $\mathrm{Pt}$, respectively. The preparation included the mixing of a $5 \mathrm{mg}$ sample with $1 \mathrm{mg}$ of carbon black (Vulcan XC-72) followed by ultrasonic dispersion of the mixture in $900 \mu \mathrm{l}$ of isopropanol and $100 \mu \mathrm{l}$ of a $0.5 \%$ Nafion solution (DuPont). The obtained ink was intensely stirred for $1 \mathrm{~h}$ A portion of $28 \mu \mathrm{l}$ was dispersed on a glassy carbon surface $\left(0.19625 \mathrm{~cm}^{2}\right)$ and left to dry naturally. The loading was $0.63 \mathrm{mg} \mathrm{cm}^{-2}$ for CoZ-68-C or $0.67 \mathrm{mg} \mathrm{cm}^{-2}$ for CoZ-69-C.
} 
(a)

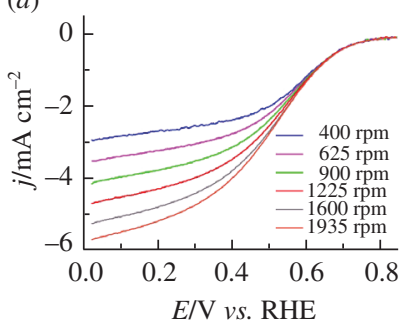

(b)

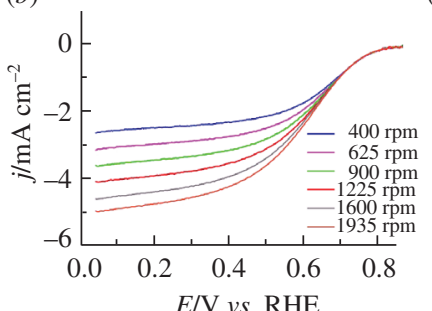

(c)

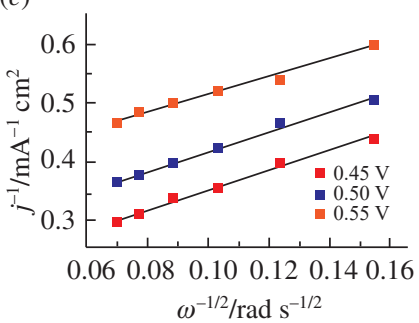

(d)

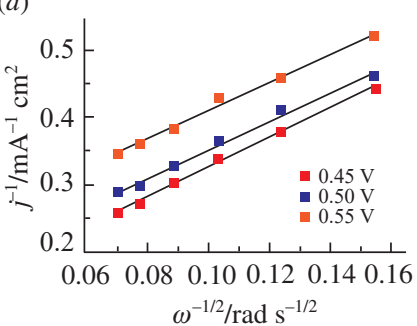

Figure 4 LSV curves at different sweep rates for (a) CoZ-68-C and (b) CoZ-69-C and the Koutecky-Levich plots for (c) CoZ-68-C and (d) CoZ-69-C

under the same conditions but in an Ar atmosphere with RDE off. According to the CV curves (Figure 3), the potentials of CoZ-68-C and CoZ-69-C changed from 0.427 to 0.374 or from 0.520 to $0.552 \mathrm{~V}$, respectively, in the 5 th and 75 th cycles. The LSV data [Figures 3(c,d)] clearly demonstrate that the half-wave potential of CoZ-69-C increased, while that of CoZ-68-C decreased. During the test, CoZ-69-C demonstrated superior absolute potential values and a shift toward higher potentials. This fact indicated that the catalyst surface was improved rather than degraded over cycling (as for CoZ-68-C).

The ORR kinetics was studied using LSV at various sweep rates of RDE [Figures $4(a, b)$ ] and calculations according to the Koutecky-Levich equation (see Online Supplementary Materials). The linear and almost parallel Koutecky-Levich plots [Figures $4(c, d)$ ] imply the first order of reaction. The electron transfer numbers from 5.0 to $5.6 \mathrm{~V}$ for CoZ-68-C and from 3.9 to $4.1 \mathrm{~V}$ for CoZ-69-C were calculated according to these plots at $0.45-0.55 \mathrm{~V}$. With no doubt, the four-electron pathway of ORR can be defined for CoZ-69-C. On the contrary, the activity of CoZ-68-C is impaired by an unknown side reaction, which may include the formation of hydrogen peroxide. The intense ORR activity of CoZ-69-C is also reflected by the higher onset and half-wave potentials. The respective values are 0.964 and $0.634 \mathrm{~V}$ in comparison to 0.852 and $0.583 \mathrm{~V}$ for CoZ-68-C.

Thus, we synthesized carbonaceous electrocatalysts from sacrificial cobalt-based ZIF-68 and ZIF-69 MOFs. The catalysts demonstrated good electrocatalytic activity in ORR with some

prevalence of CoZ-69-C. Moreover, the electron transfer number for CoZ-69-C was extremely close to 4 evidencing an efficient pathway without a by-product.

This work was supported by the Russian Science Foundation (grant no. 17-73-10386).

Online Supplementary Materials

Supplementary data associated with this article can be found in the online version at doi: 10.1016/j.mencom.2019.09.022.

\section{References}

1 (a) A. B. Kuriganova, I. N. Leontyev, O. A. Maslova and N. V. Smirnova, Mendeleev Commun., 2018, 28, 444; (b) I. N. Leontyev, D. V. Leontyeva, A. B. Kuriganova, Yu. V. Popov, O. A. Maslova, N. V. Glebova, A. A. Nechitailov, N. K. Zelenina, A. A. Tomasov, L. Hennet and N. V. Smirnova, Mendeleev Commun., 2015, 25, 468; (c) V. E. Guterman, S. V. Belenov, T. A. Lastovina, E. P. Fokina, N. V. Prutsakova and Ya. B. Konstantinova, Russ. J. Electrochem., 2011, 47, 933 (Elektrokhimiya, 2011, 47, 997).

2 D. V. Chernysheva, Y. A. Chus, V. A. Klushin, T. A. Lastovina, L. S. Pudova, N. V. Smirnova, O. A. Kravchenko, V. M. Chernyshev and V. P. Ananikov, ChemSusChem, 2018, 11, 3599.

3 B. N. Bhadra, A. Vinu, C. Serre and S. H. Jhung, Mater. Today, 2019, 25, 88 .

4 T. Lastovina, J. Pimonova and A. Budnyk, J. Phys. Conf. Ser, 2017, 829, 012007.

5 T. Palaniselvam, B. P. Biswal, R. Banerjee and S. Kurungot, Chemistry, 2013, 19, 9335 .

6 Q. Wang, W. Xia, W. Guo, L. An, D. Xia and R. Zou, Chem. Asian J., $2013,8,1879$.

7 X. Wang, J. Zhou, H. Fu, W. Li, X. Fan, G. Xin, J. Zheng and X. Li, J. Mater. Chem. A, 2014, 2, 14064.

8 (a) A. V. Stepanov, K. E. Mel'nik, V. I. Isaeva, G. I. Kapustin, V. V. Chernyshev and V. V. Veselovsky, Mendeleev Commun., 2018, 28, 88; (b) T. Lastovina, A. Budnyk, Yu. Pimonova, A. Bugaev and V. Dmitriev, Int. J. Hydrogen Energy, 2019, 44, 23010; (c) Z. Zhu, C. Chen, M. Cai, Y. Cai, H. Ju, S. Hu and M. Zhang, Mater. Res. Bull., 2019, 114, 161.

9 (a) T. Panda, K. M. Gupta, J. Jiang and R. Banerjee, CrystEngComm, 2014, 16, 4677; (b) T. Pham, K. A. Forrest, H. Furukawa, M. Russina, A. Albinati, P. A. Georgiev, J. Eckert and B. Space, J. Phys. Chem. C, 2017, 121, 1723; (c) S. Van der Perre, T. Van Assche, B. Bozbiyik, J. Lannoeye, D. E. De Vos, G. V. Baron and J. F. M. Denayer, Langmuir, 2014, 30, 8416; (d) L. Yang, L. Yu, G. Diao, M. Sun, G. Cheng and S. Chen, J. Mol. Catal. A, 2014, 392, 278.

10 X. Wen, X. Yang, M. Li, L. Bai and J. Guan, Electrochim. Acta, 2019, 296, 830 .

11 D. Zhao, X. Zhu, N. Wang, B. Lu, L. Li and S. Chen, Mater. Today, 2019, 11, 253.

12 T. A. Lastovina, A. P. Budnyk, Y. A. Pimonova, A. L. Bugaev, A. G. Fedorenko and V. P. Dmitriev, Electrochem. Commun., 2018, 88, 83.

Received: 3rd April 2019; Com. 19/5875 